\title{
IMPERATIV REINTEGRACIJE DECA POVRATNICI NA ZAPADNOM BALKANU
}

\author{
ADRIJAN ŠTUNI
}

\section{SERIJA ZA ZAPADNI BALKAN}

${ }^{66}$ Novonastala istraživanja i programi o povratnicima iz Sirije i Iraka tek počinju da se bave izazovom maloletnika povratnika.

\section{KRATKE ČINJENICE Kontekst}

$\rightarrow$ Ukupno, oko 500 stranih boraca i članova porodica sa Zapadnog Balkana ostalo je u

Siriji i Iraku.

$\rightarrow$ Navodi se da muški borci čine oko jednu trećinu lica sa Zapadnog Balkana koja su ostala u Siriji. Deca čine oko dve trećine, a žene manjinu.

$\rightarrow$ Trenutna mlada demografija stranaca povezanih sa sirijskim sukobom zahteva proaktivno delovanje, posebno uzimanje u obzir starosti i pola i odgovarajuća prilagođavanja politike odgovora u očekivanju njihove repatrijacije.
Od 2012. godine, 1070 državljana zemalja Zapadnog Balkana otišlo je da živi i bori se na teritorijama pod kontrolom terorističkih organizacija u Siriji i Iraku. Oko 200 njih su bili maloletni u vreme odlaska. Tokom godina, u sirijskom i iračkom sukobu rođeno je još mnogo dece čiji su roditelji državljani Zapadnog Balkana. Do kraja 2019. godine, oko 485 ljudi se vratilo kući, čineći Zapadni Balkan regionom sa najvećom koncentracijom povratnika iz Sirije i Iraka u Evropi. ${ }^{1}$ Još stotine njih, uglavnom maloletnika, su idalje zarobljeni u nesigurnim uslovima u Siriji,

1 NAPOMENA: Za više podataka i detaljnu procenu trenutnog stanja kontingenta stranih boraca i članova njihovih porodica na Zapadnom Balkanu, vidite: Adrian Shtuni, „Western Balkans Foreign Fighters and Homegrown Jihadis: Trends and Implications, Combating Terrorism" CTC Sentinel 12, br. 7 (13. avgust 2019.):18-24, https:// ctc. usma.edu/western-balkans-foreign-fighters-homegrownjihadis- t rends-implications/. 
sa neizvesnim izgledima za repatrijaciju. ${ }^{2}$ Brojne zemlje se sreću sa problemom šta da rade sa državljanima koji su otišli da žive i bore se u takozvanom „kalifatu“ Islamske države (IS). Međutim, iskustvo i razumevanje onoga što omogućava efikasno angažovanje u pogledu povratnika iz Sirije, naročito dece povratnika, je u ranoj fazi. U ovoj napomeni o politici daju se preporuke za načine pristupa rehabilitaciji i reintegraciji $(R \& R)$ dece povratnika na Zapadnom Balkanu, kombinujući nove prakse sa vodećim načelima konvencija, sporazuma i protokola koji se fokusiraju na prava dece.

\section{Kampovi za privremeni pritvor, početna repatrijacija i tekući izazovi}

Nakon sloma fizičkog „kalifata“ IS-a, desetine hiljada boraca koji su se predali i članova porodica nalaze se u prenatrpanim kurdskim objektima za pritvor i kampovima interno raseljenih lica (IRL). Kamp Al Hol, u kom se nalazi najviše članova porodica boraca IS-a, prihvatio je 68.823 lica u avgustu 2019. godine ${ }^{3}$ - prvobitno je predviđen za smeštaj oko sedam puta manjeg broja ljudi. ${ }^{4}$ U nedavnom izveštaju Saveta Ujedinjenih nacija za ljudska prava, uslovi u Al Holu opisani su kao „žalosni i nehumani“. ${ }^{5}$ Od ukupnog broja ljudi smeštenih u Al Holu, oko 7000 njih su strani maloletnici, a oko 3000 su žene strankinje iz oko 50 zemalja6-uključujući stotine njih sa Zapadnog Balkana.

Ukupno, oko 500 stranih boraca i članova porodica sa Zapadnog Balkana ostalo je u Siriji i Iraku. Navodi se da muški borci čine oko jednu trećinu ovog kontingenta Zapadnog Balkana, dok deca čine oko dve trećine, a žene manjinu. Mnogi od ovih boraca i članova porodica žele da se vrate u svoje matične zemlje.

Do sada, mnoge vlade nisu bile voljne da repatriraju svoje građane zbog tehničkih i pravnih poteškoća, političkih stavova i bezbednosnih razloga. ${ }^{7}$ Evropske zemlje poput Francuske, Nemačke, Holandije, Norveške i Belgije odlučile su da repatriraju - gotovo isključivo - samo nekoliko dece bez roditelja, svojih državljana koji su se pridružili IS-u. Kosovo je do sada jedna od retkih zemalja u Evropi koja je prihvatila grupnu repatrijaciju 110 državljana, od kojih su preko dve trećine (74) deca, uključujući i one koji su rođeni u Siriji i Iraku, a čiji je bar jedan roditelj državljanin Kosova. ${ }^{8}$ Krajem

2 Ibid.

3 Sirijska Arapska Republika: Severo-istočna Sirija: Kamp Al Hol“, OCHA, 1. avgust 2019. https://reliefweb.int/sites/reliefweb.int/ files/ resources/Al-Hol-Snapshot-SitRip-040819.pdf.

4 Keerthana Annamaneni, „For ISIS Children, Returning Home to Europe Meets Resistance“, The New York Times, 15. avgust 2019. https://www.nytimes.com/2019/08/15/world/europe/isis-children-belgium.html.

5 Istražna komisija Ujedinjenih nacija o Siriji, Escalating Violence and Waves of Displacement Continue to Torment Civilians during Eighth Year of Syrian Conflict (Ženeva: Savet Ujedinjenih nacija za ljudska prava, 2019.), https://www.ohchr.org/EN/ HRBodies/HRC/Pages/NewsDetail.aspx?NewsID=24972\&LangID=E.

6 Ibid.

7 Michael Birnbaum, „Months after the Fall of ISIS, Europe Has Done Little to Take Back Its Fighters“, The Washington Post, 20. jun 2019. https://www.washingtonpost.com/world/europe/after-caliphate-collapsed-europe-has-done-little-to-take-backthose-who-joined-isis/2019/06/20/4bab9cc2-8bc4-11e9-b6f4-033356502dce story.html.

8 Fatos Bytyci, „Kosovo Brings Back Fighters, Families of Jihadists from Syria“, Rojters, 20. april 2019. https://www.reuters.com/ article/us-kosovo-syria/kosovo-brings-back-fighters-families-of-jihadists-from-syria-idUSKCN1RW003. 
decembra 2019. godine, Bosna i Hercegovina je takođe repatrirala 25 svojih građana, od kojih 12 dece. $^{9}$ lako 25 repatriranih bosanskih državljana čine samo jednu desetinu ukupnog broja bosanskih državljana u sirijskim kampovima - prema zvaničnim izvorima procenjuje se da ih je $260^{10}$ - njihova repatrijacija je od velike važnosti. Spremnost Kosova i Bosne, dve inače male zemlje sa skromnim resursima, da omoguće povratak svojih građana, naročito dece, signali su da može da se smogne politička volja za rešavanje ovog trnovitog pitanja na Zapadnom Balkanu, uprkos brojnim objektivnim poteškoćama.

Ipak, druge zemlje u regionu su u velikoj meri pokazale manjak volje, odnosno manjak planova za povratak svojih državljana. Do sada nijedna druga zemlja Zapadnog Balkana nije objavila nijedan plan ili vremenski raspored repatrijacije. Jasna strategija za rešavanje ovog složenog izazova i dalje je nedostižna. Kurdski privremeni kampovi i zatvori neće omogućiti dugoročno rešenje ovog gorućeg pitanja, naročito s obzirom na to da u kontingentu stranaca koji se tamo nalaze dominiraju ranjivi maloletnici, izloženi patnji, pogodni za radikalizaciju. ${ }^{11}$ Trenutna mlada demografija stranaca povezanih sa sirijskim sukobom zahteva proaktivno delovanje, posebno uzimanje u obzir starosti i pola i odgovarajuća prilagođavanja politike odgovora u očekivanju njihove repatrijacije. To je naročito slučaj na Zapadnom Balkanu, koji ima veći broj povratnika ili onih koji će verovatno biti repatrirani, a mnogo manje u pogledu resursa, kapaciteta i stručnosti na raspolaganju za efikasno bavljenje njima, u poređenju sa većinom drugih evropskih država.

\section{Preporuke}

Novonastala istraživanja i programi o povratnicima iz Sirije i Iraka tek počinju da se bave izazovom maloletnika povratnika. Prilagođeni programi sa osvrtom na faktore starosti i pola i dalje su retki. lako je iskustvo po pitanju efikasnog angažovanja sa decom povratnicima iz Sirije i Iraka u ranoj fazi, postepeno se pojavljuju početne dobre prakse $u$ vezi sa R\&R naporima. ${ }^{12}$ Korisna istraživanja i dobre prakse iz rehabilitacionog rada sa decom-vojnicima ili maloletnicima izloženim ratnim traumama takođe mogu da pruže efikasne politike odgovora za rešavanje R\&R pitanja dece povratnika na Zapadnom Balkanu, u skladu sa vodećim konvencijama, sporazumima i protokolima u kojima se definišu prava dece.

\section{Proaktivno, transparentno i inkluzivno kreiranje politike}

$\rightarrow$ Usvojiti proaktivni i inkluzivni pristup na nivou više agencija, obavezujući se na dugoročnu R\&R strategiju. Državni organi treba proaktivno da ulažu u partnerstva na nivou više agencija i programe koji su fleksibilni, adekvatno finansirani i inkluzivni, integrišući civilno društvo na početku procesa. Međunarodni donatori i specijalizovane agencije treba

9 „Authorities Say 25 Bosnians Sent Home from Camps in Syria“, AP News, 19. decembar 2019. https://apnews.com/850b5ffb b045c65f1dfbbce52c9ff182.

10 „Bosnia: Citizens Who Fought for IS in Syria Can Return“, AP News, 11. novembar 2019. https://apnews.com/818776caf4a44 b6f97d8eb5c285ace00.

11 Savet Ujedinjenih nacija za ljudska prava, Report of the Independent International Commission of Inquiry on the Syrian Arab Republic, A/HRC/42/51 (New Yor: Generalna skupština Ujedinjenih nacija, 2019.) https://www.securitycouncilreport.org/atf/ cf/\%7B65BFCF9B-6D27-4E9C-8CD3-CF6E4FF96FF9\%7D/a hrc 42 51.pdf.

12 Za više informacija, vidite „Predloženu dodatnu literaturu, po temama“ na kraju ove Napomene o politici. 
da obezbede dodatna finansijska sredstva i napore za razvoj kapaciteta za rešavanje pitanja nedostatka resursa i stručnosti. Sa preko 400 dece i 150 žena repatriranih iz Sirije i Iraka ${ }^{13}$ do danas, napori Kazahstana mogu pružiti uvid u takav pristup. Do kraja 2019. godine, u Kazahstanu je osnovano 17 regionalnih prihvatnih i rehabilitacionih centara ${ }^{14}$ za smeštaj povratnika na neograničeni vremenski period, u zavisnosti od individualnih potreba i napretka po pitanju deradikalizacije. ${ }^{15}$ Centri ne pružaju samo usluge smeštaja, već i medicinsko i psihološko lečenje, obrazovanje, pravnu pomoć, umetničku terapiju i osposobljavanje za rad. ${ }^{16}$ Nastavni plan i program je osmišljen uz učešće grupe NVO-a, dok socijalni radnici i vladine agencije koordiniraju implementaciju programa. ${ }^{17}$

$\rightarrow$ Izraditi protokole angažovanja, prilagođene maloletnicima povratnicima, učiniti ih javnim i decentralizovati proces implementacije, gde god je to moguće. Pristup angažovanja, osmišljen na osnovu posebnih potreba maloletnika verovatno će omogućiti efikasniji psihosocijalni oporavak i ubrzanu reintegraciju dece povratnika. Publikacija ovih smernica omogućila bi dodatnu transparentnost, odgovornost i podršku procesu. Decentralizovani pristup implementacije, koji vode lokalne vlasti i NVO organizacije, verovatno će podstaći povećano angažovanje i vlasništvo nad R\&R procesom na nivou zajednice. Uprkos tome što je početkom 2020. godine repatrirala samo 17 maloletnika ${ }^{18}$, uglavnom dece bez roditelja, Francuska je izradila i objavila detaljne smernice i modalitete za tretman repatriranih francuskih i stranih maloletnika, koji su se početkom 2017. godine vratili iz Sirije i Iraka. ${ }^{19} \mathrm{U}$ strateškom dokumentu se naglašava vodeća uloga lokalnih vlasti i regionalnih kancelarija i on uključuje šemu za koordinaciju i razmenu informacija između agencija odgovornih za njegovu implementaciju.

$\rightarrow$ Okvir i pristup R\&R dece povratnika kroz objektiv obrazovanja. Iz razloga nacionalne bezbednosti, neki aspekti repatrijacije i R\&R povratnika, naročito odraslih, neizbežno su povezani sa sprovođenjem zakona i krivičnim pravom. Međutim, za decu su obrazovanje i stručno osposobljavanje neki od najvažnijih R\&R aspekata, koji nude put u novu budućnost, kao u programima reintegracije za decu-vojnike. ${ }^{20} \mathrm{~S}$ obzirom na

13 „Zhusan Operation: 595 Kazakhstanis Repatriated from Syria“, Kazinform International News Agency, 6. februar 2020. https:// www.inform.kz/en/zhusan-operation-595-kazakhstanis-repatriated-from-syria a3611674.

14 Stevan Weine „Rehabilitating the IslamicState's Womenand Children Returneesin Kazakhstan“,JustSecurity, 12. decembar 2019. https://www.justsecurity.org/67694/rehabilitating-the-islamic-states-women-and-children-returnees-in-kazakhstan/.

15 „39 Families Have Been Returned Back from Syria to Kazakhstan“, Kazakhstan Today, 18. novembar 2019. https://www.kt.kz/ eng/international affair/39 families have been returned back from syria to kazakhstan 1153667282.html

16 Ksenia Bondal, „Kazakhstan Rehabilitating Children Recently Returned from Syria, Iraq“, Caravanserai, 8. januar 2019. http:// central.asia-ews.com/en GB/articles/cnmi ca/features/2019/01/08/feature-01.

17 Andrew E. Kramer, „Kazakhstan Welcomes Women Back from the Islamic State, Warily“, The New York Times, 10. avgust 2019. https://www.nytimes.com/2019/08/10/world/europe/kazakhstan-women-islamic-state-deradicalization.html.

18 Benjamin Sportouch and Charles Deluermoz, „Enfants de jihadistes : 'Nous en avons rapatrié 17' en France, annonce Le Drian sur RTL", RTL, 2. februar 2020. https://www.rtl.fr/actu/politique/ enfants-de-jihadistes-nous-en-avons-rapatrie-17-en-france-annonce-le-drian-sur-rtl-7800014980.

19 Kancelarija premijera vlade Francuske, Instruction relative à la prise en charge des mineurs à leur retour de zone irakosyrienne, Dopis br. 5923/SG (Pariz: Vlada Francuske, mart 2017.) http://circulaires.legifrance.gouv.fr/ pdf/2017/03/ cir 41965.pdf.

20 Kancelarija specijalnog predstavnika generalnog sekretara za decu i oružane sukobe, Reintegration of Former Child Soldiers (Njujork: Sekretarijat Ujedinjenih nacija, 2018.) https://childrenandarmedconflict.un.org/wp-content/uploads/2018/09/ 
to, odgovarajuća ministarstva obrazovanja svake zemlje Zapadnog Balkana, na primer, mogu biti u boljem položaju i pogodnija od ministarstava unutrašnjih poslova kada je reč o vođenju i koordinaciji rehabilitacije dece uključene u nasilni ekstremistički sukob. Izbor ministarstva je važan zato što odražava i saopštava javnosti sveukupan način razmišljanja vlade po pitanju angažovanja. U Kazahstanu je vlada odlučila da Ministarstvo obrazovanja bude zaduženo za program R\&R. Njihovo iskustvo može pružiti neke korisne uvide u tom pogledu. ${ }^{21}$

\section{Zaštititi dete i pružiti mu podršku}

$\rightarrow$ Podržati mere kojima se prioritizuje najbolji interes dece povratnika i najbrža razumna $R \& R$ u glavne društvene tokove. Pravosudne institucije treba da delaju u skladu sa međunarodnim pravom i važećim standardima maloletničkog pravosuđa. U slučajevima kada je krivično gonjenje dece mlađe od 18 godina zagarantovano, u skladu sa Konvencijom o pravima deteta treba razmotriti alternative pritvoru i lišavanju slobode. ${ }^{22}$ Rezolucija Generalne skupštine 70/291 o Pregledu Globalne strategije Ujedinjenih nacija za borbu protiv terorizma bavi se ovim konkretnim pitanjem i treba je konsultovati prilikom izrade odgovarajućih pravnih mehanizama. ${ }^{23}$

$\rightarrow$ Izvršiti procene rizika i potreba, u cilju procene mentalnog blagostanja i nivoa traume dece povratnika pre pružanja psiho-socijalne podrške, prilagođene individualnim potrebama. Deca povratnici bila su izložena delima ekstremnog nasilja i, u nekim slučajevima, možda su i sama direktno preživela ekstremno nasilje. U drugim slučajevima, ona su možda učestvovala u izvršenju nasilnih ekstremističkih dela. Agencije nadležne za javno zdravlje treba da sprovode detaljne i periodične procene, kako bi zasebno procenile svaki slučaj. ${ }^{24}$ Kako su neka starija deca povratnici verovatno bila podvrgnuta nasilnoj ekstremističkoj indoktrinaciji i obuci dok su bila u Siriji i Iraku, vlasti treba da procene potencijalni rizik koji predstavljaju i pruže specijalizovanu negu za rešavanje njihove indoktrinacije i obuke pre njihovog prelaska u javno obrazovno okruženje. Krajem aprila 2019. godine, Kosovo je repatriralo 74 maloletnika iz Sirije. Do septembra, sva deca školskog uzrasta među tim povratnicima bila su

Reintergration-brochure-layout.pdf; Skënder Perteshi i Ramadan Ilazi, Unpacking Kosovo's Response to Returnees from the War Zones in Syria and Iraq (Priština: Kosovski centar za bezbednosne studije, 2020.) http://www.qkss.org/repository/docs/ violent-extremism-eng 978757.pdf.

Weine, „Rehabilitacija žena i dece povratnika Islamske države u Kazahstanu“.

Konvencija o pravima deteta (Njujork: Generalna skupština Ujedinjenih nacija, 1989. godine), https://www.ohchr.org/en/ profes- sionalinterest/pages/crc.aspx; Kancelarija Ujedinjenih nacija za borbu protiv terorizma (UNCCT), Children Affected by the Foreign-fighter Phenomenon: Ensuring a Child Rights-based Approach (New York: UNCCT, 2019.) https://www. un.org/counterterrorism/ctitf/sites/www.un.org.counterterrorism.ctitf/files/ftf handbook web reduced.pdf.

23 Generalna skupština Ujedinjenih nacija, 70. zasedanje, „Resolution 70/291 [The United Nations Global Counter-Terrorism Strategy Review]“ (A/RES/70/291), 1. jul 2016. godine, https://www.un.org/sc/ctc/news/ document/a-res-70-291-the-united-nations-global-counter-terrorism-strategy-review/.

Organizacija za evropsku bezbednost i saradnju (OEBS), Non-custodial Rehabilitation and Reintegration in Preventing and Countering Violent Extremism and Radicalization That Lead to Terrorism A Guidebook for Policymakers and Practitioners in South-Eastern Europe (Vienna, OSCE, 2020.) https://www.osce.org/secretariat/444838?download=true. 
spremna za polazak u školu. ${ }^{25} \mathrm{~S}$ obzirom na to da je njihova efikasna inkluzija u mejnstrim društvo krajnji cilj napora za reintegraciju, upis dece povratnika je pozitivan korak. Ipak, nejasno je koliko prilagođenu psihološku i akademsku podršku su dobili pre upisa u državne škole nekoliko meseci nakon povratka.

$\rightarrow$ Sprovesti psihometrijske testove za procenu intelektualnog razvoja dece povratnika, kako bi se osigurao adekvatan smeštaj u obrazovni sistem i po potrebi pružila akademska pomoć. Ovi napori će verovatno biti efikasniji ako deca ne budu institucionalizovana, već dobiju akademsku obuku i psihološku pomoć kod kuće, eventualno od strane mobilnih timova stručnjaka. To može pomoći da se izbegne osećaj neadekvatnosti, stigme i potencijalne marginalizacije, sve dok povratnicima ne bude prijatnije u novom društvenom okruženju. Na primer, u Francuskoj, nakon što tužilac i sudija za maloletnike procene slučaj bilo kog deteta povratnika, maloletnici dobijaju somatski i psihološki pregled, pod brigom socijalnih službi. Odluke o školovanju donose se uz konsultacije između akademskog direktora nacionalnih obrazovnih službi, obrazovnih institucija i praktičara koji implementiraju i nadgledaju R\&R napore. ${ }^{26}$

\section{Zaključak}

Na kraju, uspešna rehabilitacija i reintegracija dece povratnika će zahtevati usvajanje holističke strategije psiho-socijalne podrške, koja će se baviti svim aspektima njihove socijalne interakcije i reintegracije u kući, školi i zajednici. Kao takav, na napredak svakog deteta povratnika na R\&R putu snažno će uticati pogled na svet i stav roditelja i rođaka koji žive sa njima. Stoga, programi treba da pruže širu podršku za rešavanje pitanja radikalizacije nasilja i traume u celoj porodici. Takođe, nastavnici i drugi praktičari uključeni u proces obrazovanja i rehabilitacije dece povratnika treba da prođu obuku o svesti o traumi i dobiju informacije o procesu radikalizacije, uključujući i kako odgovoriti na znake zabrinjavajućeg ponašanja i gde zatražiti dodatnu podršku. Sa poboljšanim znanjem, veštinama i alatima za rešavanje zabrinutosti zajednica koje primaju povratnike i stvarnosti iskustava povratnika, zemlje Zapadnog Balkana mogu da omoguće laganiju i sigurniju tranziciju povratnika u mejnstrim društvo.

25 Taulant Qenaj, „Fëmijët e Kthyer Nga Siria, Sërish Në Shkolla“, Radio Evropa e Lirë, 27. avgust 2019. https://www.evropaelire. org/a/femijet-e-kthyer-nga-siria-shkollim-/30130050.html.

26 Kancelarija premijera vlade Francuske, Instruction relative à la prise en charge des mineurs à leur retour de zone irakosyrienne, Dopis br. 5923/SG. 


\section{Predložena dodatna literatura, po temama}

\section{O regrutovanju i eksploataciji dece od strane terorista}

Bloom Mia i John Horgan. Small Arms: Children and Terrorism. Ithaca, New York: Cornell University Press, 2019.

United Nations Office on Drugs and Crime (UNODC). Handbook on Children Recruited and Exploited by Terrorist and Violent Extremist Groups: The Role of the Justice System. Vienna: UNODC, 2017. https://www.unodc.org/documents/justice-and-prison-reform/Child-Victims/Handbook on Children Recruited and Exploited by Terrorist and Violent Extremist Groups the Role of the Justice System.E.pdf.

\section{O deci povezanoj sa terorističkim organizacijama u Siriji i Iraku}

Cook Joana i Gina Valle. „From Daesh to 'Diaspora' II: The Challenges Posed by Women and Minors After the Fall of the Caliphate". CTC Sentinel 12, br. 6 (jul 2019.): 30-45. (jul 2019.) https://ctc.usma. edu/daesh-diaspora-challenges-posed-women-minors-fall-caliphate/.

\section{O rehabilitaciji i reintegraciji dece}

Meines, Marije Merel Molenkamp, Omar Ramadan i Magnus Ranstorp. RAN Manual: Responses to Returnees: Foreign Terrorist Fighters and their Families. Amsterdam: Radicalisation Awareness Network (RAN) Centre of Excellence, 2017. https://ec.europa.eu/home-affairs/sites/homeaffairs/ files/ ran br a4 m10 en.pdf.

The Global Counterterrorism Forum (GCTF). Good Practices on Addressing the Challenge of Returning Families of Foreign Terrorist Fighters. GCTF, 2018. https://www.thegctf.org/Portals/1/Docu- ments/ Framework\%20Documents/2018/GCTF-Good-Practices-on-Returning-Families-of-FTFs ENG. pdf?ver=2018-09-25-101427-323.

United Nations. Key Principles for the Protection, Repatriation, Prosecution, Rehabilitation and Reintegration of Women and Children with Links to United Nations Listed Terrorist Groups. United Nations, 2019. https://www.un.org/counterterrorism/ctitf/sites/www.un.org.counterterrorism.ctitf/files/ Key\%20 Principles\%20-\%20April\%202019 0.pdf.

United Nations Office of Counter-terrorism (UNCCT). Children Affected by the Foreign-fighter Phenomenon: Ensuring a Child Rights-based Approach. New York: UNCCT, 2019. https://www.un.org/counterterrorism/ctitf/sites/www.un.org.counterterrorism.ctitf/files/ftf handbook web reduced.pdf

United Nations Office on Drugs and Crime (UNODC). Roadmap on the Treatment of Children Associated with Terrorist and Violent Extremist Groups. Vienna: UNODC, 2019. https://indd.adobe.com/ view/61793921-8dc6-4fc2-9e46-b27c6390fff2.

Liesbeth van der Heide i Jip Geenen. Children of the Caliphate: Young IS Returnees and the Reintegration Challenge. The Hague: International Centre for Counter-terrorism - The Hague, 2017. https://icct. nl/wp-content/uploads/2017/08/ICCT-vanderHeide-Geenen-Children-of-the-Caliphate-2.pdf.

\section{O izazovima sa kojima se suočavaju praktičari koji rade sa decom povratnicima}

Radicalisation Awareness Network (RAN). Child Returnees from Conflict Zones. Amsterdam: RAN Centre of Excellence, 2016. https://ec.europa.eu/home-affairs/sites/homeaffairs/files/what-we-do/ networks/radicalisation awareness network/ran-papers/docs/issue paper child returnees from conflict zones 112016 en.pdf. 


\section{Izvori}

„39 Families Have Been Returned Back from Syria to Kazakhstan“. Kazakhstan Today, 18. novembar 2019. https://www.kt.kz/eng/ international affair/39 families have been returned back from syria to kazakhstan 1153667282.html.

Annamaneni Keerthana. „For ISIS Children, Returning Home to Europe Meets Resistance“ The New York Times, 15. avgust 2019. https://www.nytimes.com/2019/08/15/world/europe/isis-children-belgium.html.

„Authorities Say 25 Bosnians Sent Home from Camps in Syria“. AP News, 19. decembar 2019. https://apnews.com/850b5ffbb045 c65f1dfbbce52c9ff182.

Birnbaum Michael. „Months after the Fall of ISIS, Europe Has Done Little to Take Back Its Fighters". The Washington Post, 20. jun 2019. https://www.washingtonpost.com/world/europe/after-caliphate-collapsed-europe-has-done-little-to-take-backthose-who-joined-isis/2019/06/20/4bab9cc2-8bc4-11e9-b6f4-033356502dce story.html.

Bondal Ksenia. „Kazakhstan Rehabilitating Children Recently Returned from Syria, Iraq“. Caravanserai, 8. januar 2019. http:// central.asia-ews.com/en GB/articles/cnmi ca/features/2019/01/08/feature-01.

„Bosnia: Citizens Who Fought for IS in Syria Can Return“. AP News, 11. novembar 2019. https://apnews.com/818776caf4a44b6f 97d8eb5c285ace00.

Bytyci Fatos. „Kosovo Brings Back Fighters, Families of Jihadists from Syria“. Rojters, 20. april 2019. https://www.reuters.com/ article/us-kosovo-syria/kosovo-brings-back-fighters-families-of-jihadists-from-syria-idUSKCN1RW003.

Kramer, Andrew E. „Kazakhstan Welcomes Women Back from the Islamic State, Warily“. The New York Times, 10. avgust 2019. https://www.nytimes.com/2019/08/10/world/europe/kazakhstan-women-islamic-state-deradicalization.html.

Office of the Special Representative of the Secretary-General for Children and Armed Conflict. Reintegration of Former Child Soldiers. New York: United Nations Secretariat, 2018. https://childrenandarmedconflict.un.org/wp-content/uploads/2018/09/ Reintergration-brochure-layout.pdf.

Organization for Security and Co-operation in Europe (OSCE). Non-custodial Rehabilitation and Reintegration in Preventing and Countering Violent Extremism and Radicalization That Lead to Terrorism A Guidebook for Policymakers and Practitioners in South-Eastern Europe. Vienna, OSCE, 2020. https://www.osce.org/secretariat/444838?download=true.

Perteshi Skënder i Ramadan Ilazi. Unpacking Kosovo's Response to Returnees from the War Zones in Syria and Iraq. Priština: Kosovar Centre for Security Studies, 2020. http://www.qkss.org/repository/docs/violent-extremism-eng 978757.pdf.

Prime Minister's Office of the Government of France. Instruction relative à la prise en charge des mineurs à leur retour de zone irakosyrienne, Circular No. 5923/SG. Paris: Government of France, mart 2017. http://circulaires.legifrance.gouv.fr/ pdf/2017/03/ cir 41965.pdf.

Qenaj Taulant. „Fëmijët e Kthyer Nga Siria, Sërish Në Shkolla“. Radio Evropa e Lirë, 27. avgust 2019. https://www.evropaelire. org/a/femijet-e-kthyer-nga-siria-shkollim-/30130050.html.

Shtuni Adrian. „Western Balkans Foreign Fighters and Homegrown Jihadis: Trends and Implications, Combating Terrorism". CTC Sentinel 12, br. 7 (13. avgust 2019.):18-24. https://ctc.usma.edu/western-balkans-foreign-fighters-homegrown-jihadistrends-implications/.

Sportouch Benjamin i Charles Deluermoz. „Enfants de jihadistes: 'Nous en avons rapatrié 17' en France, annonce Le Drian sur RTL". RTL, 2. februar 2020. https://www.rtl.fr/actu/politique/enfants-de-jihadistes-nous-en-avons-rapatrie-17-en-franceannonce-le-drian-sur-rtl-7800014980. 
„Syrian Arab Republic: North East Syria: Al Hol Camp“. OCHA, 1. avgust 2019. https://reliefweb.int/sites/reliefweb.int/files/ resources/Al-Hol-Snapshot-SitRip-040819.pdf.

United Nations Commission of Inquiry on Syria. Escalating Violence and Waves of Displacement Continue to Torment Civilians during Eighth Year of Syrian Conflict. Geneva: United Nations Human Rights Council, 2019. https://www.ohchr.org/EN/

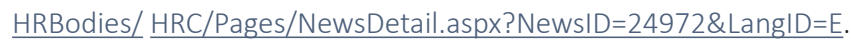

United Nations General Assembly. Convention on the Rights of the Child. New York: United Nations General Assembly, 1989. https://www.ohchr.org/en/professionalinterest/pages/crc.aspx.

- - , 70th Session. „Resolution 70/291 [The United Nations Global Counter-Terrorism Strategy Review]“(A/RES/70/291) 1.jul 2016. https://www.un.org/sc/ctc/news/document/a-res-70-291-the-united-nations-global-counter-terrorism-strategy-review/.

United Nations Human Rights Council. Report of the Independent International Commission of Inquiry on the Syrian Arab Republic, A/ HRC/42/51. New York: United Nations General Assembly, 2019. https://www.securitycouncilreport.org/atf/cf/\%7B65BFCF9B6D27-4E9C-8CD3-CF6E4FF96FF9\%7D/a hrc 42 51.pdf.

United Nations Office of Counter-terrorism (UNCCT). Children Affected by the Foreign-fighter Phenomenon: Ensuring a Child Rightsbased Approach. New York: UNCCT, 2019. https://www.un.org/counterterrorism/ctitf/sites/www.un.org.counterterrorism. ctitf/files/ftf handbook web reduced.pdf.

Weine Stevan. „Rehabilitating the Islamic State's Women and Children Returnees in Kazakhstan“. Just Security, 12. decembar 2019. https://www.justsecurity.org/67694/rehabilitating-the-islamic-states-women-and-children-returnees-in-kazakhstan/.

„Zhusan Operation: 595 Kazakhstanis Repatriated from Syria“. Kazinform International News Agency, 6. februar 2020. https:// www.inform.kz/en/zhusan-operation-595-kazakhstanis-repatriated-from-syria a3611674. 


\section{O napomeni}

Autor: Adrijan Štuni, generalni direktor kompanije Shtuni Consulting LLC, specijalista je za spoljnu politiku, bezbednost i strateške komunikacije sa regionalnim fokusom na Zapadni Balkan. Radi kao konsultant američkih vladinih agencija, akademskih institucija $i$ međunarodnih organizacija u Sjedinjenim Državama, Evropi i Aziji, u vezi sa borbom protiv nasilnog ekstremizma, antiterorizmom, političkim rizikom, suzbijanjem strane propagande i dezinformacija, kao i drugim transnacionalnim pretnjama.

Stavovi izraženi u ovoj publikaciji su stavovi autora. Oni nužno ne odražavaju stavove RESOLVE mreže, isntituta U.S. Institute of Peace ili bilo kog tela američke vlade.

RESOLVE MREŽA

bolje istraživanje.informisana praksa•poboljšana politika protiv nasilnog ekstremizma.

www.resolvenet.org

y $f$ in 